work. This result may well have delayed the introduction of flooding. Nevertheless, undoubtedly behaviourism has provided a framework for the development of behaviour therapy, which has been a framework for the application of common sense. The link may be tenuous-a controversial theory of psychosexual development provided a framework for the development of individual psychotherapy-but the need for these frameworks must surely tell us something about human psychology.

${ }^{1}$ Beech, H R, in A Textbook of Human Psychology, eds H J Eysenck and G D Wilson. Lancaster, Medical and Technical Publishing, 1976.

2 Pavlov, I P, Conditioned Reflexes. London, Oxford University Press, 1927.

3 Watson, J B, and Rayner, R, fournal of Experimental Psychology, 1920, 3, 1.

${ }^{4}$ Marks, I M, American Fournal of Psychiatry, 1976, 133, 253.

5 Siligman, M E P, in The Psychology of Depression: Contemporary Theory and Research, eds R J Friedman and M M Katz. New York, John Wiley, 1974.

6 Yates, A J, Theory and Practice in Behaviour Therapy. New York, John Wiley, 1975.

${ }^{7}$ Lazarus, A A, Psychological Reports, 1971, 28, 349.

${ }^{8}$ Masserman, J H, Behaviour and Neurosis. Chicago, University of Chicago Press, 1943.

\section{Hairy legs}

Methods tried to remove hair ${ }^{1}$ from the legs have included use of the arsenic compound orpiment, hot leeches, ants' eggs, and the blood of yellow frogs. One at least of these, arcana, a syrup of sugar and water laid on the hairs and stripped off when dry, is still used for the legs in some parts of the Middle East-together with another traditional method, the plucking of hairs by a rapidly moving loop of twisted thread. ${ }^{2}$

Hair may be removed ${ }^{3} 4$ at the surface (depilation) by shaving, chemical degradation, and abrasion; or from the roots (epilation) by wax-the counterpart of sugar syrup-and electrolysis. Shaving is simple and cheap. Any subsequent dryness can be kept to a minimum by the use of bland creams. Shaving does not make the hair regrow faster or thicker, but has to be done frequently, and the regrowing hair has a bristly truncated end. The popular depilatory creams, sprays, and lotions are generally based on thioglycollates with calcium hydroxide or some other alkali; this combination has largely supplanted the sulphides of barium, strontium, and calcium and is less smelly. It is left on for five to 15 minutes and is then washed off. The regrowing hair is less bristly than after shaving, and, though there may be slight irritation of the skin, allergy is rare. Abrasion, though somewhat hard on the skin, can remove a light growth. Both pumice stone and sandpaper mitts to slip over the hands are available.

Waxes are usually applied warm, though a few may be used cold. The wax sets, and at a crucial moment (which is a matter of nice judgment) is pulled off with its embedded hairs. Areas of up to a few centimetres across are dealt with in succession. Some hairs may break below the surface and inflammation supervene as they grow, but this is unusual with wax-though Dilaimy ${ }^{2}$ found that it was common with the sugar syrup and thread methods. Much depends on the operator's skill, and a salon treatment may be a good investment. The regrowing hair feels natural and allergic reactions are rare. The process has to be repeated after a few weeks. Electrolygists assert that wax distorts the follicle, making later electrolysis difficult.

Permanent removal of hairs by electrolysis (galvanic or with short-wave diathermy) is formidably slow and expensive, even on facial hair; it may be surprising that it is in demand for hair on the legs. The procedure is safe if carried out by a welltrained operator, but even with frequent treatment would take at least two years. ${ }^{5}$ That it should be contemplated owes much to current mores, in which exposure to the sun of a body exiguously clad is thought to have snob value. Removal of hair from the genitocrural area ("the bikini line") may be requested, and other methods are difficult there. A new method of epilation, in which the current passes down the hair as opposed to coming from a needle inserted in the follicle, has yet to be assessed as regards safety and efficacy. Self-operated electrolysis gadgets are not to be advised.

Most women will have no difficulty in choosing a method acceptable to their individual liking and need. Racial and cultural factors affect the type of hair and attitudes towards it. Views may be changing, however: already some younger women are leaving body hair alone. The reason may be current fashion, indolence, a respect for untouched nature, women' lib, or some other individual attitude. Who can say what the custom will be ten years from now ?

1 Maxwell-Hudson, C, Kaleidoscope of Beauty. London, Octagon Press, 1968.

2 Dilaimy, M, Archives of Dermatology, 1976, 112, 507.

${ }^{3}$ Lancet, 1967, 1, 488.

4 Ridley, C M, British fournal of Dermatology, 1969, 81, 146.

5 The Permanent Removal of Superfuous Hair by Electrolysis. Blackburn, The Institute of Electrolysis.

\section{Pulmonary complications of measles}

In measles the rash is a cardinal feature, but it is possible to have measles without a rash. Disease in the respiratory tract, however, is invariable, and this is true not only of wild measles, where cough or croup precede the rash, but also of the mild reactions occasionally encountered with modern attenuated measles vaccines. Moreover, secondary pulmonary infection in measles is well known and is a recognised cause of death in measles.

What is the nature of these pulmonary changes? Measles is acquired by droplet spread, and the virus gains access to the respiratory passages by direct inoculation of the mucous membranes. Controversy still surrounds the possibility that the conjunctivae are a portal of entry, though there is experimental evidence supporting this possibility. ${ }^{1}$ At all events the virus reaches the mucosa of the respiratory tract either by droplet inoculation or by passage down the nasolachrymal sac to reach the nose.

In the respiratory epithelium the characteristic response is the formation of multinucleate giant cells. These giant cells have been described in many tissues and secretions, such as the pharynx, nasal mucosa, skin, appendix, sputum, and urine..$^{2-4}$ Indeed, the presence of giant cells in scrapings of nasal mucosa or in the urine can give laboratory support to the diagnosis of measles before the onset of the rash in much the same way as Koplik spots support the early clinical diagnosis.

Like Koplik spots giant cells are transient. They are part of the pathological evolution of the illness; they come and they go. In very few cases they persist, and in these patients the fine crepitations and high fever characteristic of early measles continue, with the development of viral pneumonitis. The onset of giant cell pneumonia at this stage of measles is probably rare. Another form of giant cell pneumonia is a 